\title{
NILAI PENDIDIKAN KARAKTER DALAM CERITA ANAK "DOA UNTUK AMANG KANI" KARYA SITI MAKIAH
}

\section{CHARACTER EDUCATION VALUE IN THE CHILDREN'S STORY "DOA UNTUK AMANG KANI" BY SITI MAKIAH}

\author{
Jahdiah \\ Balai Bahasa Kalimantan Selatan \\ Jalan A. Yani Km. 32, Loktabat Utara, Banjarbaru Utara, Kalimantan Selatan \\ Pos-el: diah.banjar@yahoo.co.id
}

*) Naskah diterima: 21 Februari 2020; direvisi: 21 Februari 2020; disetujui: 19 Oktober 2020

\begin{abstract}
Abstrak
Cerita anak termasuk dalam sastra anak yang disajikan khusus untuk anak-anak. Tulisan ini bertujuan mendeskripsikan nilai-nilai pendidikan karakter dalam cerita anak "Doa untuk Amang Kani".Masalah yang diangkat dalam penelitian ini adalah nilai-nilai pendidikan karakter apa saja yang ada dalam cerita anak "Doa untuk Amang Kani" dan indikator apa saja yang ada dalam setiap nilai pendidikan karakter tersebut. Penelitian ini termasuk penelitian kuantitatif dengan menggunakan metode deskriptif. Teknik yang digunakan dalam penelitian ini adalah teknik catat. Hasil analisis data bahwa dalam cerita anak Doa untuk Amang Kani terdapat lima nilai pendidikan karakter, yaitu (1) keimanan dan ketakwaan, (2) kejujuran. (3) kecerdasan (4) ketangguhan, dan (5) kepedulian. Kelima nilai pendidikan karakter tersebut masing-masing mempunyai indikator.
\end{abstract}

Kata kunci: cerita anak, nilai pendidikan karakter, dan indikator

\begin{abstract}
Children story is catagorized in children literature especially presented for children. This writing is aimed to describe the values of character education in children's story Doa untuk Amang. It is quantitative study using descriptive method. The technique used in this study is note taking. The result shows that there are five character education values, they are (1) belief and piety, (2) honesty, (3) intelligence, (4) firmness, and (5) concern. Each of these five character education values has indicator.
\end{abstract}

Keywords: children's story, character education, indicator.

\section{PENDAHULUAN}

Salah satu cabang kebudayaan yang sangat berperan di dalam membudayakan manusia adalah sastra. Ada dua alasan yang mendukung pernyataan ini. Pertama, sastra merupakan karya seni (budaya manusia) yang sudah lama ada di antara manusia. Sastra ada sejak manusia mampu mengelola bunyi-bunyi yang dihasilkan oleh alat ucap- nya menjadi sistem bahasa. Kedua, bahasa sebagai media sastra merupakan unsur budaya yang sangat akrab dengan kehidupan manusia (Effendi dan Sabhan, 2007: $1)$.

Sastra merupakan sarana untuk Melalui karya sastra, terutama sastra anak mengajarkan berbagai nilai dalam kehidupan, di antaranya moral, sosial, dan psikologi. 
Melalui sastra orang dapat meresapi secara imajinasi kepentingan di luar dirinya (Sayuti dalam (Sarumpaet, 2002:40).

Salah satu sastra yang dikenal di Indonesia adalah jenis sastra anak. Sastra anak merupakan karya yang dari segi bahasa mempunyai nilai estetis dan dari segi isi bahasa mengandung nilai-nilai pendidikan moral yang dapat memperkaya pengalaman jiwa bagi anak (Pramuki, 2000:34) menegaskan bahwa sastra anak adalah karya sastra (puisi, prosa, dan drama) yang isinya mengenai anak-anak sesuai kehidupan, kesenangan, sifat-sifat, danperkembangan anak.

Cerita anak adalah cerita kesederhanaan yang komplek. Kesederhanaan itu ditandai oleh syarat wacana yang baku dan berkualitas tinggi, tidak ruwet sehingga komunikatif. Kompleksitas cerita anak ditandai oleh struktur yang tidak berbeda dari struktur fiksi untuk orang dewasa (Rampan, 2003:89).

Cerita atau sastra anak yang baik harus menarik. Hal ini yang harus diperhatikan dalam sastra anak. Cerita anak akan menarik jika dikembangkan antara elemennya secara seimbang sehingga setiap elemen struktur saling mengisidan tidak ada bagian yang kurang atau berlebihan (Hayati, 2015:82).

Ada tiga syarat karya sastra dikatakan sastra anak, yaitu (1) jika tokoh utamanya adalah anak-anak, (2) hubungan ide, tema, dan bahasa berbentuk sederhana, dan juga berisi ajaran moral (Obi, dkk., 2010).

Sastra anak sebagai karya sastra yang dikonsumsi oleh anak-anak pada rentang usia bayi sampai dengan remaja. Sastra anak menawarkan dua hal utama, yaitu kesenangan dan pemahaman (Lucken, 2003:10). Sastra anak adalah sastra yang secara emosionalpsikologis dapat ditanggapi dan dipahami oleh anak yang berangkat dari fakta konkret yang dapat diimajinasikan (Nurgiyantoro, 2005:6).
Cerita anak "Doa untuk Amang Kani" karya Siti Makiah merupakan salah satu cerita dari pemenang bahan bacaan literasi yang diadakan oleh Balai Bahasa Kalimantan Selatan. Cerita ini dapat digolongkan ke dalam cerita anak atau sastra anak yang banyak berisi nilai-nilai karakter pendidikan. Sastra anak diyakini memiliki kontribuasi yang besar bagi perkembangan kepribadian anak dalam proses menuju kedewasaan. Sastra anak diyakini mampu digunakan sebagai salah satu sarana menanamkan, memupuk, mengembangkan bahkan melestarikan nilai-nilai pendidikan yang baik dan sangat berharga bagi keluarga, masyarakat, dan bangsa (Wianti, 2014:1).

Sastra anak dikatakan mempunyai nilai pendidikan yang baik apabila (1)mampu mengembangkan kemampuan anak, (2) mempu mengembangkan kemampuan bercerita, (3) mempu mengembangkan kemampuan membaca, (4) mampu menunjang kemampuan menulis, dan (5) mampu memperluas wawasan khasanah sastra anak (Carol Lynch Brow dan Carl M Tomlison, 1993:21).

Bertolak dari beberapa pendapat di atas, karya sastra, terutama sastra anak secara tidak langsung membentuk karakter individu. Karakter merupakan cara berpikir dan berperilaku yang menjadi ciri khas setiap individu untuk hidup dan bekerja sama.

Beberapa penelitian yang pernah dilakukan yang berkaitan dengan cerita anak adalah (Hasimah, 2015) dengan judul Kelangsungan Moral dalam Karya Sastra Anak. Tulisan tersebut membahas nilai moral dalam cerita anak Anak muda Lindungan Bulan. Sementara itu, dalam penelitian Analisis Nilai Karakter dalam Cerita Anak KecilKecil Punya Karya (Wianti, 2014) menguraikan nilai karakter yang ada dalam cerita anak Kecil-Kecil Punya Karya, yaitu (1) 
religius yang berhubungan dengan (a) mengerjakan sholat, (b) rasa syukur, (2) nilai pendidikan karakter jujuryang berhubungan dengan (a) diri sendiri dan (b) jujur dengan orang lain, (3) toleransi, (4) disiplin (5) kerja keras, (6) kreatif, (7) mandiri, (8) demokratis, (9) rasa ingin tahu, (10) cinta tanah air, (11) menghargai prestasi, (12) bersahabat, (13) cinta damai, (14) gemar membaca, (15) peduli sosial, (16) tanggung jawab. Selain itu, tulisan yang membahas cerita anak adalah Kajian Sastra Anak KecilKecil Punya Karya The Evergreen Karya Nisrina Hanifah dalam Perspektif Pendidikan Karakter karya (Sugiati, 2013). Tulisan tersebut menunjukkan bahwa dalam cerita anak terdapat aspek kebahasaanyang diketahui melalui struktur kalimat dan diksi.

Berbeda dengan penelitian terdahulu, penelitian ini membahas nilai-nilai pendidikan karakter yang ada dalam cerita anak "Doa untuk Amang Kani" dengan indikator masing-masing serta sebagai penentu nilai karakter pendidikan.

Masalah dalam penelitian ini adalah nilai pendidikan karakter apa saja yang terdapat dalam cerita anak "Doa untuk Amang Kani" dan indikator apa yang ada dalam setiap nilai pendidikan karekter tersebut.

\section{LANDASAN TEORI}

Karakter merupakan nilai-nilai perilaku manusia. Karakter berhubungan dengan Tuhan Yang Maha Esa, diri sendiri, sesama manusia, lingkungan, dan kebangsaan. Karakter terwujud dalam pikiran, sikap, perasaan, perkataan, dan perbuatan berdasarkan norma-norma agama, hukum, tata krama, budaya, dan adat istiadat.

Pendidikan karakter merupakan isu yang paling banyak dibicarakan akhir-akhir ini. Fenomena ketidakjujuran di dalam kehidupan bermasyarakat dan bernegara mencetuskan diskusi pentingnya pendidik- an karakter bangsa (Hasanuddin, 2013:13). Nilai-nilai pendidikan karakter dapat bersumber dari berbagai hal.

Secara umum menurut Prayitno dan Afriva Khaidir (dalam Hasanuddin, 2015) menjelaskan bahwa ada lima fokus kebenaran dengan nilai-nilai karakter dan kecerdasan, yaitu:

1. Keimanan dan ketakwaan, dengan indikator perilaku percaya pada Tuhan yang Maha Esa, mengerjakan perintah dan meninggalkan larangan Tuhan, amanah, bersyukur, dan ikhlas.

2. Kejujuran dengan indikator perilaku berkata apa adanya, berbuat atas dasar kebenaran bertanggung jawab, memenuhi kewajiban dan menerima hak, lapang dada, memegang janji.

3. Kecerdasan dengan indikator perilaku aktif, dinamis, berpikir logis, analitis, mampu mencari solusi, berpikir positif, dan maju serta terbaik.

4. Ketangguhan dengan indikator perilaku teliti, sportif, sabar, disiplin, ulet atau tidak mudah putus asa, bekerja keras, berani menanggung resiko, menjaga keselamatan dan kesehatan diri.

5. Kepedulian dengan indikator perilaku patuh pada aturan, sopan santun, demokratis, toleransi, suka membantu, pemaaf, menjaga kerahasian.

\section{METODE PENELITIAN}

Metode yang digunakan dalam penelitian ini adalah metode deskriptif. Metode deskriptif adalah metode yang digunakan dengan tidak menggunakan angka-angka, tetapi menggunakan penghayatan terhadap interaksi terhadap konsep yang sedang dikaji secara empiris (Semi, 2012:23). Metode kualitatif adalah metode metode yang paling cocok untuk fenomena sastra (Nurgiyantoro, 2005:5). Moleong, (2000: 5)menyatakan bahwa penelitian deskriptif 
kualitatif adalah gabungan antara metode deskriptif dan kualitatif.

Model penelitian kualitatif adalah prosedur penelitian yang menghasilkandata deskriptif berupa kata-kata tertulis atau lisan tentang orang-orang dan perilaku yang diamati. Teknik pengumpulan data dilakukan dengan menggunakan teknik catat, yaitu dengan membaca isi cerita "Doa untuk Amang Kani" secara keseluruhan kemudian mencatat kalimat-kalimat atau paragraf yang berisi nilai karakter pendidikan. Data-data itu kemudian dianalisis untuk mencari nilai karakter pendidikan sesuai dengan teori yang digunakan.

\section{HASIL DAN PEMBAHASAN}

Cerita anak mempunyai andil yang besar bagi perkembangan kepribadian anak dalam proses menuju kedewasaan. Cerita anak diyakini mampu digunakan sebagai salah satu sarana untuk menanamkan, memupuk, dan mengembangkan nilai-nilai pendidikan karakter yang baik dan sangat berharga bagi keluarga, masyarakat, dan bangsa.

\section{Sinopsis}

Cerita anak "Doa untuk Amang Kani" karya Siti Makiah menceritakan tokoh Hamid dan teman-temannya mengerjakan tugas dari sekolah. Mereka membuat patung dari kayu. Hamid, Sabran, Bayah, dan Halimah berkumpul untuk membuat tugas dari sekolah. Tugas dari sekolah ini dikerjakan berkelompok. Di rumah Hamid mereka berdiskusi untuk membuat tugas tersebut. Mereka berencana mencari sejenis kayu pulatan yang akan mereka gunakan sebagai bahan untuk membuat patung. Dengan dibantu oleh ayah Halimah, mereka mencari kayu pulatan yang tumbuh di sekitar kampung mereka.

Minggu pagi mereka kembali berkumpul di rumah Halimah. Mereka sangat antu- sias mengerjakan tugas dari guru untuk membuat patung dari kayu pulatan. Patung yang mereka buat adalah patung kura-kura. Karena mereka baru belajar membuat patung dari kayu, hasilnya tidak sesuai dengan yang diharapkan. Mereka saling mentertawakan hasil buatan mereka.

Siang itu mereka bertemu di rumah Hamid. Mereka bersiap di tempat Paman Ahim di hilir desa untuk mencari pohon rambai. Setelahitu, mereka kembali mencari kayu rambai yang merupakan bahan dasar untuk membuat patung ular karena akar rambai memanjang. Setelah sepakat, mereka pergi ke hilir desa untuk mencari kayu rambai. Mereka menemui beberapa pohon yang tumbuh liar di sepanjang sungai.

Hamidah, salah satu dari mereka, dengan lancar dan serba tahu menerangkan nama-nama pohon dan tumbuhan serta manfaatnya masing-masing. Teman-teman yang lain seperti, Sabran, Hamid, dan Bayah hanya mendengarkan sambil sesekali bertanya dan kagum kepada Halimah yang pengetahuan luas karena sering membaca buku. Sedang asyik-asyiknya menebang pohon rambai, mereka melihat ada yang memperhatikan dari kejauhan. Seorang lakilaki saparuh baya yang mereka kenal dengan nama Amang Kani. Hamid dan kawankawan terkejut dan langsung lari karena ketakutan sehingga parang dan kayu rambai yang mereka cari tertinggal.

Selesai makan malam, Hamid menceritakan pengalamannya bertemu Amang Kani dengan orang tuanya. Orang tua Hamid menceritakan asal mula Amang Kani sakit jiwa karena kehilangan anak sewaktu kebakaran rumahnya beberapa tahun yang lalu. Amang Kani merasa bersalah karena tidak bisa menolong anaknya ketika kebakaran terjadi. Amang Kani yang bermaksud mengangkat anaknya ternyata salah mengangkat. Amang Kani malahan membawa guling yang dikira anaknya. Semenjak 
itu jiwa Amang Kani terganggu dan sering hilir mudik di kampung sambil membawa ember. Keluarga Hamid sepakat untuk membawa Amang Kani ke rumah sakit jiwa untuk pengobatan.

Senin, setelah selesai upacara bendera, siswa kelas enam masuk ke kelas. Mereka mulai belajar. Sabran membukabungkusan hasil yang mereka kerjakanbersama Hamid dan teman-temannya. Setelah diumumkan ternyata kelompok Hamid dan kawankawan mendapat nilai terbaik. Mereka senang dan gembira karena hasil kerja keras mereka selama ini tidak sia-sia.

Ketika jam pelajaran berakhir, Hamid, Sabran, Halimah, dan Bayah bergegas keluar kelas dan berjanji untuk pulang bersama. Di depan sekolah mereka berpapasan dengan rombongan kepala desa, petugas kesehatan, dan Paman Iril. Mereka ingin menjemput Amang Kani untuk dibawa berobat ke rumah sakit. Mereka senang karena sekarang Amang Kani sudah dapat perhatian dari warga untuk diberikan pengobatan. Semoga Amang Kani dapat sembuh seperti sedia kala. Mereka berdoa untuk kesembuhan Amang Kani.

\section{Nilai Pendidikan Karakter dalam Cerita Anak "Doa untuk Amang Kani"} a. Nilai-nilai Pendidikan Karakter K-
eimanan dan Ketakwaan

Nilai-nilai pendidikan karakter keimanan dan ketakwaan dapat ditelusuri melalui indikator sikap dan perilaku percaya pada Tuhan yang Maha Esa, mengerjakan perintah dan meninggalkan larangan, amanah, bersyukur, dan iklas. Berikut analisis nilai pendidikan karakter dalampendidikan karakter keimanan dan ketakwaan dalam cerita anak "Doa untuk Amang Kani"

\section{Data 1}

"Sebentar lagi waktu salat Magrib, ayo masuk" kata ibu sambil berjalan menuju belakang untuk berwudhu. "Siap, mama sayang!" kata Hamid mengikuti ibunya (Makiah, 2019:3).

Teks kutipan tersebut memperlihatkan ibu Hamid menjalankan amanah Tuhan dengan mengingatkan anaknya agar Hamid mengerjakan perintah Allah, yaitu salat Magrib. Ibu Hamid mengingatkan agar Hamid segera wudhu untuk salat Magrib.Kutipan tuturan tokoh ibu pada data (1) mempunyai indikator sikap dan perilaku keimanan dan ketakwaan kepada Tuhan dengan mengingatkan anaknya untuk segera salat. Berikut nilai pendidikan karakter yang terdapat dalam cerita anak "Doa untuk Amang Kani".

\section{Data 2}

"Mari kita sama-sama berdoa. Semoga dengan kerja sama berbagai pihak, beliau dapat segera sembuh dari sakitnya dan bisa hidup normal seperti masyarakat umumnya!" kata Hamid sambil menengadahkan tangan.

"Amin!" kata mereka serentak (Makiah, 2019:34).

Kutipan tersebut memperlihatkan bahwa tokoh dalam cerita tersebut mengajak teman-temannya untuk berdoa agar Amang Kani yang mengalami gangguan jiwa cepat sembuh. Kutipan dalam data di atas memperlihatkan adanya nilai pendidikan karakter keimanan dan ketakwaan. Dengan mengajak berdoa untuk kesembuhan Amang Kani, tokoh dalam cerita mempunyai rasa ketakwaan. Indikator nilai pendidikan karakter ditunjukkan dengan mengajak teman-temannya untuk selalu bersyukur. 
b. Nilai Pendidikan Karakter Kepedulian Nilai-nilai pendidkan karakter kepedulian dapat ditelusuri melalui indikator sikap dan perilaku patuh pada aturan atau norma sopan santun, demokratis, tolerensi, suka membantu, damai, anti kekerasan, pemaaf, dan menjaga kerahasiaan. Berikut analisis nilai pendidikan karakter dalam cerita anak "Doa untuk Amang Kani".

Data 3

"Halimah, ada ayahmu dalam rombongan itu" kata Sabran.

"Iya, tadi beliau bercerita mau tempat Paman Ahim bersama kepala desa untuk melakukan pendekatan kepada Amang Kani, karena Paman Ahimlah yang paling dekat dan sering bertemu Amang Kani, kata Halimah." Ada ayahmu juga, Mid! Kata Sabran. "Iya, ayahku seorang petugas kesehatan, jadi memang tugas beliau membantu mengurusi pasien, termasuk pasien jiwa,"kata Hamid (Makiah, 2019:26).

Kutipan tersebut menceritakan tokoh Hamid dan teman-temannya melihat rombongan petugas kesehatan dari puskesmas sedang menuju rumah Amang Kaniuntuk membawanya berobat ke rumah sakit jiwa. Kutipan di atas menyatakan adanya nilainilai pendidikan karakter kepedulian. Indikator nilai karakter kepedulian ditunjukkan dengan menolong sesama. Dalam kutipan tersebut, warga berusaha agar Amang Kanicepat sembuh.

\section{Data 4}

"Penanganan bagi orang yang terindikasi gangguan jiwa ada prosedurnya, petugas mengumpulkan data dari laporan bidan desa, kader, masyarakat atau sekelompok masyarakat tentang pasien, Kemudian dilakukan kunjungan, pengkajian, dan pemeriksaan serta analisis data. Selanjutnya berkalobarisi dengan tim medis dalam pemberian terapi dan melaksanakan rujukan ke tempat perawatan jiwa," kata ayah menambahkan.

"Insyaaalah! Besok ayah mencari informasi dulu karena sudah lama meninggalkan desa ini."

"Amin" kata Hamid (Makiah, 2019:25).

Kutipan di atas menceritakan tokoh Hamid mendengarkan penjelasan dari ayahnya terkait cara penanganan orang dengan gangguan jiwa. Pak Hamid berniat membawa Amang Kani untuk diobati. Kutipan pada data di atas memperlihatkan adanya nilai pendidikan karakter kepedulian terhadap sesama. Nilai pendidikan kepedulian dapat dilihat dari indikator sikap tolerensi, suka membantu. Pada kutipan di atas terlihat jelas bahwa keluarga Hamid berusaha menolong Amang Kani untuk diobati.

\section{Data5}

"Rumah pamanmu jauh sekali ya, Mah. Tidak takut apa, terpisah dari masyarakat desa kita?" tanya Hamid.

"Paman Ahim punya usaha penggilingan padi. Takut limbah padi dan suara mesin menganggu lingkungan. Jadi, memang harus agak menjauh dari masyarakat umum (Makiah, 2019:14).

Kutipan di atas berisi dialog Hamid dan teman-temannya ketika sedang mencari kayu. Di tengah perjalanan mereka melihat penggilangan padi milik Paman Ahim. Kutipan dalam data (5) berisi nilai karakter kepedulian. Nilai pendidikan kepedulian terlihat dari indikator toleransi. Indikator 
toleransi terlihat dari upaya Paman Ahim mendirikan pengilingan padi jauh dari rumah penduduk. Hal tersebut dilakukan supaya suara mesin penggilingan padi tidak menganggu penduduk.

c. Nilai-nilai Pendidikan Karakter Kecerdasan

Nilai-nilai pendidikan karakter kecerdasan dapat ditelusuri melalui indikator sikap perilaku aktif, dinamis, berpikir logis, analitis, mampu mencari solusi, berpikir maju, dan konsisten. Berikut nilai pendidikan karakter kecerdasan dalam cerita "Doa untuk Amang Kani".

Data 6

Sabtu sore di teras rumah Halimah, Hamid, Sabran, Bayah, dan Halimah berkumpul. Mereka berencana mengerjakan tugas sekolah membuat patung.

"Kita membuat patung kura-kura saja," usul Bayah.

"Bahan apa?" tanya Hamid

"Kelompok lain menggunakan tanah liat. Kalau kita sebaiknya menggunakan kayu saja, pasti unik kalau kita membuat patung kayu,"kata Bayah (Makiah, 2019:4).

Kutipan di atas merupakan penggambaran dari tokoh-tokoh dalam cerita "Doa untuk Amang Kani". Kutipan tersebut memperlihatkan kegiatan Hamid dan kawankawannya yang sedang membuat tugas kelompok, yaitu patung dari kayu. Mereka saling mengusulkan agar tugas sekolah yang mereka buat mendapat nilai yang terbaik. Kutipan tersebut mempunyai nilai pendidikan karakter kecerdasan. Nilai pendidikan kecerdasan ditunjukkan oleh tokoh Bayah yang mengusulkan membuat patung dari kayu. Indikator dari nilai pendidikan karakter kecerdasan, yaitu mampu memberi solusi. Tokoh Bayah mampu memberikan solusi kepada temantemannya agar membuat karya berbeda dengan kelompok yang lain supaya ada nilai lebih.

\section{Data7}

“Tenang Mid! Aku juga tahu beberapa jenis pohon di desa kita ini," kata Sabran.

Setelah meminjam parang kepada Paman Ahim, mereka berjalan melewati kebun Paman Ahim yang ditanami pisang, jambu, dan mangga menuju ke pinggir sungai.

"Itu pohon bungur" kata Halimah dambil menunjuk beberapa pohon sejenis.

“Dari mana kamu tahu?" tanya Bayah.

"Lihat bunganya berkelompok di ujung rantai, sangat cantik bila mekar bersama, warna merah muda keunguan. Anggap saja Sakuranya Indonesia, walaupun tumbuh juga di India dan Firlandia. Kalau di daerah kita biasanya tumbuh liar di daerah tepian sungai,"Halimah menjelaskan (Makiah, 2019:16).

Kutipan di atas merupakan kutipan alur dari cerita yang menggambarkan ketika Hamid dan teman-temannya mencari kayu untuk membuat hasta karya di sekolah. Dalam kutipan di atas Sabran menjelaskan tentang pohon yang mereka temui di pinggir sungai kepada teman-temannya yang tidak mengetahui pohon-pohon yang ada di sekitar mereka. Kutipan pada data di atas mempunyai nilai pendidikan karakter kecerdasan. Hal tersebut dapat dilihat dari indikator berpikir yang diperlihatkan oleh tokoh Sabran yang banyak mengetahui pohon-pohon yang ada. 
d. Nilai-Nilai Pendidian Kejujuran

Nilai-nilai pendidikan karakter kejujuran dapat ditelusuri melalui indikator sikap dan perilaku berkata apa adanya, berbuat atas dasar kebenaran, bertanggung jawab, memenuhi kewajiban, bertanggung jawab, lapang dada, dan memegang janji. Berikut analisis nilai pendidikan karakter kejujuran dalam cerita anak "Doa untuk Amang Kani".

\section{Data8}

"Apa sebaiknya kita buatkan ayahnya Sabran saja, ya?" tanya Halimah.

"Iya sebaiknya kita minta buatkan ayahmu saja biar hasilnya bagus dan kelompokkita mendapatkan nilai tertinggi?" bujuk Bayah.

"Berarti bukan kerja kelompok kita, tapi kerja ayah Sabran," kata Hamid.

"Sejelek apapun hasil kerja kita, kita harus bangga dengan hasil kerja kita sendiri." katanya menambahkan.

"Tapi kan kita harus dapat nilai bagus, malu kalau kelompok kita kalah dengan kelompok lain,"kata Bayah terus membujuk.

"Lebih malu lagi kalau dapat nilai tinggi tapi hasil karya orang lain" balas Hamid (Makiah, 2019:8).

Hamid tidak setuju usul teman-temannya yang mengusulkan bahwa sebaiknya mereka meminta bantuan ayah Sabran untuk menyelasaikan tugas kelompok dari sekolah karena merasa bahwa hasil karya mereka tidak bagus dan selalu gagal membuat patung dari kayu yang mirip dengan aslinya.Hamid meyakinkan temantemannya untuk tidak menyerahkan tugas yang bukan karya sendiri. Tugas yang mereka kumpulkan harus dikerjakan sendiri. Hal tersebut termasuk nilai pen- didikan karakter kejujuran dengan indikator berbuat atas dasar kebenaran.

Data9

Sabran juga tidak ketinggalan mengecat patung ulat dan kura-kura buatannyadengan warna yang mirip sekali sedangkan Halimah dan Hamid mencoba berbagai motif dan warna. "kura-kura buatan ayahmu saja yang dikumpul juga, Bran!"Saran Bayah.

“Cukup punya aku saja yang dikumpulkan, punya ayah disimpan di rumah saja, bisa jadi penyemangat saat aku belajar," kata Sabran.

"Setuju! Semua patung yang kita serahkan pada Pak Guru harus buatan kita sendiri,"kata Hamid bersemangat (Makiah, 2019:31).

Kutipan di atas menyatakan bahwa tokoh Sabran juga mempunyai prinsip sama dengan tokoh Hamid, yaitu hasil kerja kelompok saja yang dikumpulkan ke guru walaupun ada patung kayu buatan ayah Sabran yang lebih bagus hasilnya. Sikap yang dimiliki tokoh Sabran ini memperlihatkan nilai pendidikan karakter kejujuran dengan indikator bertanggung jawab. Tokoh Hamid juga mendukung apa yang dikatakan oleh tokoh Sabran. Mereka bertanggung jawab atas hasil kerja yang mereka kerjakan walaupun hasilnya tidak sebagus karya ayah Sabran.

\section{Data 10}

Pak Gunawan sebagai wali kelas enam sangat merasa sangat senang akan hasil karya siswanya. Beliau memberikan pujian kepada setiap kelompok, walaupun dengan pemberian nilai yang berbeda sesuai dengan kriteria penilaian yang sudah ditentukan. “Kelompok dengan karya terbaik diperoleh Sabran dan kawan-kawan, 
untuk itu mereka mendapat nilai yang sangat baik," kata Pak Gunawan setelah melakukan penilaian diikuti oleh tepuk tangan siswa (Makiah, 2019:3).

Kutipan di atas memperlihatkan alur cerita mengenai penilaian hasil hasta karya Sabran dan teman-temannya. Tokoh Pak Gunawan memperlihatkan seseorang yang berbuat atas dasar kebenaran. Hal ini sesuai salah satu indikator dari nilai pendidikan karakter kejujuran. Pak Gunawan memberikan nilai terbaik kepada kelompok Sabran dan kawan-kawannya karena terbaik hasilnya, sikap inilah yang diyakini berbuat atas dasar kebenaran.

\section{e. Nilai Pendidikan Ketangguhan}

Nilai-nilai pendidikan karakter ketangguhan dapat ditelusuri melalui indikator sikap dan perilaku teliti, sportif, sabar, disiplin, tidak mudah putus asa, bekerja keras, berani menanggung resiko, dan menjaga keselamatan diri.

\section{Data 11}

Dengan susah payah, Sabran menggunakan alat-alat pertukangan ayahnya, sedangkan Hamid membantu sebisanya. Namun, menggunakan gerjaji tidak semudah yang mereka bayangkan, apalagi menggunakan pahat, mereka baru pertama kali memegang.

Dengan sudah payah, Sabran dan Hamid tetap mencoba memotong dan memahat. Masing-masing membuat membuat kura-kura dari potongan kayu, meskipun lunak tetap memerlukan keterampilan dan keahlian dalam membuatnya (Makiah, 2019:8).

Kutipan di atas menceritakan tokoh Sabran dan Hamid yang berusaha dengan segala tenaga dan kemampuan mereka membuatpatung dari kayu. Kutipan pada data 11 di atas mengemukakan nilai pendidikan karakter ketangguhan. Nilai pendidikan karakter ketangguhan ada pada tokoh Sabran dan Hamid yang berusaha membuat patung buatan sendiri. Nilai karakter pendidikan tersebut dengan indikator tidak mudah putus asa dan bekerja keras yang tercemin melalui tokoh Sabran dan Hamid.

\section{Data 12}

“Coba cari ide yang lain, misalnya menggunakan bahan tanah liat, atau bahan lain" beliau menyarankan.

"Kalau bahan tanah liat sudah dipilih kelompok lain, kami harus menggunakan bahan yang berbeda," kata Halimah (Makiah, 2019:8).

Kutipan pada data 12 di atas menceritakan tokoh Halimah yang ingin karya kelompok mereka berbeda dengan kelompok yang lain agar mempunyai nilai lebih dan hal yang baru. Kutipan cerita anak di atas mempunyai nilai pendidikan karakter ketangguhan dengan indikator orientasi pada kualitas/mutu. Dalam hal ini, tokoh Halimah ingin karya mereka berbeda dengan kelompok lain dengan mencari bahan membuat patung dari kayu bukan dari tanah liat.

\section{PENUTUP}

Karya sastra anak sangat bagus untuk dibaca karena berisi nilai-nilaipendidikan karakterdalam cerita anak Doa untuk Amang Kani. Berdasarkan hasil analisis di atas dapat disimpulkan bahwa dalam cerita tersebut terdapat nilai pendidikan karakter sebagai berikut (1) sikap perilaku keimanan dan ketakwaan dengan indikator yang terdapat dalam cerita tersebut meliputi mengerjakan perintah dan meninggalkan larangan, yaitu perintah salat yang wajib 
dikerjakan sebagai seorang muslim, (2)nilai pendidikan karakter kepedulian dengan indikator menolong sesama dan peduli pada lingkungan, (3) nilai pendidikan karakter kecerdasan dengan indikator berpikir dan mampu memberi solusi, (4) nilai pendidikan karakter kejujuran dengan indikator bertanggung jawab dan berbuat atas dasar kebenaran, dan (5) nilai pendidikan karakter ketanguhan dengan indikator tidak mudah putus asa, bekerja keras, dan oritentasi pada kualitas atau mutu.

\section{DAFTAR PUSTAKA}

Carol Lynch Brow dan Carl M Tomlison. 1993. Essential s of Children 's Literature. New York: Northem Illnois University.

Effendi, Rustam dan Sabhan. 2017. Sastra Daerah. Banjarmasin: PBS FKIP Universitas Lambung Mangkurat.

Hasanuddin. 2015. Sastra Anak:Kajian Tema, Amanat, dan Teknik Penyampaian Cerita Anak Terbitan Surat Kabar. Bandung: Angkasa.

Hasimah, N. dkk. 2015. Kelangsungan Moral dalam Karya Sastra KanakKanak. In R. Nurfaidah (Ed.), Seminar Internasional Sastra. Bandung: UNPAD Press.

Hayati, Y. 2015. Menulis (kembali) Sastra Anak dalam Sejarah Sastra Indonesia. In R. dkk. Nurfaidah (Ed.), Seminar Internasional Sastra. Bandung: UNPAD Press.
Lucken, R. J. 2003. Citical handbook of Childrens Literature. New York: Longman.

Moleong. L.J. 2000. Metode Penelitian Kualitatif. Bandung: Remaja Rosdakarya. Nurgiyantoro, B. 2005. Sastra Anak:Pengantar, Pemahaman, Dunia Anak. Yogjakarta: Gajahmada University Press.

Obi, C. dkk. (2010). Children's Literature. Nigeria: University of Nigeria.

Pramuki, E. 2000). Apresiasi Karya Sstra Anak Secara Reseptif. Jakarta: Universitas Terbuka.

Rampan, K. L. 2003. Teknik Menulis Cerita Anak. Yogyakarta: Pinkbook.

Sarumpaet, R. T. 2002. Sastra Masuk Sekolah. Yogyakarta: Penerbit Indonesia Tera.

Semi, M.2012. Metode Penelitian Sastra. Bandung: Angkasa Jaya.

Siti, Makiah. 2019. “Doa Untuk Amang Kani". Banjarbaru

Sugiati. 2013. Kajian Sastra Anak "KecilKecil Punya Karya The Evergrean Karya Nisrina Hanifah dalam Perspektif Pendidikan. Jurnal Humanity, 8(2).

Wianti, F. 2014. “Analisis Nilai Karakter dalam Cerita Anak Kecil-Kecil Punya Karya". Universitas Syiah Kuala. 